\title{
Enterovirus infection of the stomach in chronic fatigue syndrome/myalgic encephalomyelitis
}

\author{
Jonathan R Kerr
}

Chronic fatigue syndrome/myalgic encephalomyelitis (CFS/ME) is a disease characterised by severe and debilitating fatigue, sleep abnormalities, impaired memory and concentration, and musculoskeletal pain. ${ }^{1}$ In the Western world, the population prevalence is estimated to be of the order of $0.5 \% .^{2{ }^{3}}$ Research studies have identified various features relevant to the pathogenesis of CFS/ME such as viral infection, immune abnormalities and immune activation, exposure to toxins, chemicals and pesticides, stress, hypotension, lymphocyte abnormalities and neuroendocrine dysfunction. However, the precise underlying disease mechanisms and means by which these abnormalities inter-relate in patients with CFS/ME, remain to be clarified. ${ }^{45}$

Various viruses have been shown to play a triggering or perpetuating role, or both, in this complex disease. Microbes which have been shown to trigger CFS/ $\mathrm{ME}$ include enteroviruses, Epstein-Barr virus, Chlamydia pneumoniae, parvovirus B19, Coxiella burnetii, Borna disease virus, varicella zoster virus, cytomegalovirus, and human herpesvirus type 6 (HHV-6). Chronic microbial infections which have been documented in patients with CFS/ ME include C burnetii, parvovirus B19, C pneumoniae, hepatitis $C$, enteroviruses and human retroviruses. Virus reactivations in $\mathrm{CFS} / \mathrm{ME}$ include varicella zoster virus, herpes simplex virus (increased frequency of cold sores) and Epstein-Barr virus. ${ }^{5}$

The role of enterovirus (EV) infection as a trigger and perpetuating factor in $\mathrm{CFS} / \mathrm{ME}$ has been recognised for decades. In 1988, it was shown that replication competent enteroviruses could be cultured from the faeces of 17 of 76 patients with CFS/ME compared with only 2 of 30 matched controls; further sampling of

Correspondence to: Dr J R Kerr, CFS Group, Dept of Cellular and Molecular Medicine, St George's University of London, Cranmer Terrace, London SW17 ORE, UK; jkerr@sgul.ac.uk these patients demonstrated culture of the same virus in five patients (29\%). ${ }^{6}$ Using a monoclonal antibody, enterovirus VP1 protein was detected in the circulation of 44 of 87 patients with CFS/ME. ${ }^{6}$ In view of the tropism of enteroviruses for skeletal and cardiac muscle, research focused on enterovirus infection of skeletal muscle. Studies demonstrated a higher frequency of enterovirus infection of skeletal muscle in patients with CFS/ME compared with that in normal controls ${ }^{7-9}$; enterovirus infection of skeletal muscle was therefore proposed as the likely disease mechanism. However, several negative studies ${ }^{10-12}$ combined with the rise of the psychiatric "biopsychosocial model" of CFS/ME have led to a diminished interest in this area.

The importance of gastrointestinal symptoms in CFS/ME $\mathrm{ME}^{13-15}$ and the known ability of enteroviruses to cause gastrointestinal infections, ${ }^{16}$ led John and Andrew Chia to study the role of enterovirus infection in the stomach of patients with CFS/ME. In this issue, they describe a systematic study of enterovirus infection in the stomach of 165 patients with CFS/ME, demonstrating a detection rate of EV VP1 protein of $82 \%$ in patients with CFS/ME compared with $20 \%$ in normal controls. ${ }^{17}$ Gastric biopsies from six patients with CFS/ME with repeat specimens 2-8 years later showed positive staining for EV VP1. EV RNA was detected in 9/24 (37\%) paraffin-embedded biopsy samples, compared with only $1 / 21$ controls. One of three patients tested had detectable EV RNA from two samples taken 4 years apart. Five patient samples showed transient growth of non-cytopathic enteroviruses. ${ }^{17}$ These intriguing data for which there is ample supporting data (briefly described above) strongly suggest a new and hitherto unrecognised disease mechanism in patients with CFS/ $\mathrm{ME}$, which in my opinion, could trigger and perpetuate this disease. But, as with all discoveries, many new questions are raised.

The possibility that this cohort represents the result of an EV outbreak has been considered by the authors, but seems unlikely as these patients developed their disease at different times over a 20 year period. The fact that so many EV infections were diagnosed in one clinic is probably due to the persevering interest of the authors in EV infections in CFS/ME and their diligent studies over many years.

The possibility that in this cohort, EV infection triggered and perpetuated the disease in all 135 of the 165 patients with CFS/ME (those positive for EV infection) seems unlikely for the following reasons: some of these patients were positive for enterovirus prior to development of CFS/ $\mathrm{ME}$; infection with some of the 70 known enteroviruses seemed not to trigger CFS/ $M E$, but superinfection with a different enterovirus strain did trigger CFS/ME; and a large number of viruses and insults are known to act as triggers for the disease. The possibility exists that EV infection of the stomach is an epiphenomenon in patients with CFS/ME, accounting only for the gastrointestinal symptoms, but I seriously doubt that this is true, given the systemic inflammation found in association with other stomach infections, such as Helicobacter pylori.

It seems likely that skeletal muscle EV infection would be less common than stomach EV infection as this organism primarily infects the gastrointestinal tract. Published studies of the prevalence of EV infection of skeletal muscle in CFS/ ME support this, some of which are positive $^{7-9}$ and some negative. ${ }^{10-12}$ In view of the link between EV infection of skeletal muscle and abnormal lactate response to exercise, ${ }^{18}$ it is possible that in an EV infected patient with CFS/ME, the extent of EV infection may determine severity; for example, skeletal muscle infection in addition to stomach infection.

Does the presence of gastrointestinal complaints in a patient with CFS/ME indicate a high probability that the disease has been triggered and is being perpetuated by an EV infection? The answer is "yes" in the Torrance cohort, but is as yet undetermined in other patients with CFS/ $M E$. The role of $E V$ infection of the stomach in the pathogenesis of irritable bowel syndrome also needs to be clarified in light of these results.

What is the biological nature and replication competence of the EVs isolated from the stomach of patients with CFS/ $\mathrm{ME}$ compared with those isolated from 
faeces during an acute infection? This is an important issue and one which is already being studied by these authors.

In conclusion, enterovirus stomach infection in patients with CFS/ME is described for the first time by John and Andrew Chia (father and son), who are to be congratulated on a highly original and thorough study which is immensely valuable to the field. We must now determine how this fits in with what is already known of the pathogenesis of this elusive disease.

Competing interests: None declared.

Accepted 6 September 2007

Published Online First 14 September 2007

J Clin Pathol 2008;61:1-2. doi:10.1136/jcp.2007.051342

\section{REFERENCES}

1. Fukuda K, Straus SE, Hickie I, et al. The chronic fatigue syndrome: a comprehensive approach to its definition and study. International Chronic Fatigue Syndrome Study Group. Ann Intern Med 1994;121:953-9.
2. Department of Health. Report of the CFS/ME Working Group. Department of Health, January 2002 (http://www.dh.gov.uk/en/Publicationsandstatistics/ Publications/PublicationsPolicyAndGuidance/ DH_4064840) (accessed 5 Nov 2007)

3. Papanicolaou DA, Amsterdam JD, Levine S, et al. Neuroendocrine aspects of chronic fatigue syndrome. Neuroimmunomodulation 2004;11:65-74.

4. Komaroff AL, Buchwald D. Chronic fatigue syndrome: an update. Annu Rev Med 1998;49:1-13.

5. Devanur LD, Kerr JR. Chronic fatigue syndrome. J Clin Virol 2006:37:139-50.

6. Yousef GE, Isenberg DA, Mowbray JF. Detection of enteroviral-specific RNA sequence in muscle biopsy specimens from patients with adult-onset myositis. Ann Rheum Dis 1990;49:310-5.

7. Nairn C, Galbraith DN, Clements GB. Comparison of coxsackie B neutralization and enteroviral PCR in chronic fatigue patients. J Med Virol 1995;46:310-3.

8. Gow JW, Behan WMH, Clements GB, et al. Enteroviral RNA sequences detected by polymerase chain reaction in muscle of patients with post-viral fatigue syndrome. BMJ 1991:302:692-6.

9. Cunningham L, Bowles NE, Lane RJM, et al. Persistence of enteroviral RNA in chronic fatigue syndrome is associated with abnormal production of equal amounts of positive and negative strands of enteroviral RNA. J Gen Virol 1990;71:1399-402.

10. Gow JW, Behan WMH, Simpson K, et al. Studies on enterovirus in patients with chronic fatigue syndrome Clin Infect Dis 1994:18(Suppl):S126-9.
11. McArdle A, McArdle F, Jackson MJ, et al. Investigation by polymerase chain reaction of enteroviral infection in patients with chronic fatigue syndrome. Clin Sci 1996:90:295-300.

12. Lindh G, Samuelson A, Hedlund KO, et al. No finding of enteroviruses in Swedish patients with chronic fatigue syndrome. Scand J Infect Dis 1996;28:305-7.

13. Carruthers BM, Jain AK, De Meirleir KL, et al Myalgic encephalomyelitis/chronic fatigue syndrome: clinical working case definition, diagnostic and treatment protocols. Journal of Chronic Fatigue Syndrome 2003;11:7-36.

14. Frissora CL, Koch KL. Symptom overlap and comorbidity of irritable bowel syndrome with other conditions. Curr Gastroenterol Rep 2005;7:26471.

15. Henningsen $\mathbf{P}$, Zimmermann T, Sattel H. Medically unexplained physical symptoms, anxiety, and depression: a meta-analytic review. Psychosom Med 2003;65:528-33.

16. Oberste MS, Pallansch M. Establishing evidence for enterovirus infection in chronic diseases. Ann NY Acad Sci 2003;1005:23-31.

17. Chia JK, Chia AY. Chronic fatigue syndrome is associated with chronic enterovirus infection of the stomach. J Clin Pathol 2008;61:43-8.

18. Lane RJ, Soteriou BA, Zhang $\mathrm{H}$, et al. Enterovirus related metabolic myopathy: a postviral fatigue syndrome. J Neurol Neurosurg Psychiatry 2003;74:1382-6. 